\title{
O discurso hegemônico de Veja e a construção da imagem do pobre
}

Maria Aparecida Baccega

Coordenadora adjunta do Programa de Mestrado Comunicaşão e Práticas de Consumo

da Escola Superior de Propaganda e Marketing de São Paulo.

Professora livre-docente aposentada do Departamento de Comunicações

e Artes da Escola de Comunicações e Artes da Universidade de São Paulo.

E-mail: mabga@usp.br

Aline Fernandes de Azevedo

Jornalista pela Unesp, mestranda da Escola de Comunicações e Artes

da Universidade de São Paulo.

E-mail: azevedo.aline@gmail.com

Este artigo pretende analisar e refletir sobre as formas do discurso da revista semanal Veja, bem como examinar sua atuação no mercado editorial brasileiro e a dimensão que a publicação ocupa na sociedade contemporânea como difusora dos modos de ser e pensar de determinado segmento dessa mesma sociedade. Nosso principal ponto de interesse é relatar como a marca Veja constrói e veicula a imagem dos pobres através da leitura da edição 1972 de 6 de setembro de $2006^{1}$.

De fato, diante da legitimidade construída desde seu nascimento em plena ditadura militar em 1968, a publicação, idealizada por Roberto Civita nos moldes das norte-americanas Times e Newsweek, pode ser classificada como a principal revista de assuntos gerais e atualidades da maior empresa editorial do gênero no Brasil: a Editora Abril. A publicação sofreu com a censura após o AI-5, libertando-se em 1975 depois da saída de seu coordenador inicial, jornalista Mino Carta, em episódio de conhecimento público ${ }^{2}$. Paralelamente, teve sérios problemas de aceitação durante os primeiros seis anos, devido à preferência do leitor pelo formato do magazine ilustrado Manchete, e só saiu do vermelho em 1974, quando começou a vender assinaturas. Após a saída de Mino Carta, assumiram dois redatores-chefes: José Roberto Guzzo e Sérgio Pompeu. Foi quando a revista passou a priorizar o furo de reportagem, incorporando o impacto como ponto essencial de constituição de seu discurso. Dessa forma, acompanhando o processo de redemocratização nacional, passando pelo regime autoritário e pelos anos que se seguem à abertura democrática, a publicação chega à era da globalização como uma revista que se considera de denúncia,

1. VEJA. São Paulo: Ed. Abril, ano 39, n. 35, p. 64, ed. 1972,6 set. 2006 .

2. Ver FÍGARO, Roseli. Mino, jornalista de opinião. Comunicação \& Educação, São Paulo: CCA-ECA-USP/ Salesiana, n. 23, p. 71-90, jan./abr. 2002. CARTA, Mino. O castelo de âmbar. São Paulo: Record, 2000. 400 p. 
3. GREGOLIN, Maria do Rosário Valencise. Michel Pêcheux e a história epistemológica da lingüística. In: FONSECA-SILVA, M. C.; SANTOS, E. (Orgs.). Estudos da língua(gem). Vitória da Conquista: Edicões Uesb - Universidade Estadual do Sudoeste da Bahia, n. 1, jun. 2005 p.106.

4. DUAILIBI, Julia. Dividir para governar. Veja, São Paulo: Ed. Abril, ano 39, n. 35 , p. 64 , ed. 1972,6 set. 2006.

5. FIORIN, J. L. Linguagem e ideologia. São Paulo: Ática, 2003. p. 42

6. BAKHTIN, M. Marxismo e filosofia da linguagem. Trad. Michel Lahud et al. São Paulo: Hucitec, 1978. p. 47. que privilegia temas políticos e persegue as chamadas notícias quentes, tendo como principal estratégia discursiva o lema informação com interpretação.

Dessa forma, diante do destaque das publicações no cenário midiático nacional, nosso texto procura desvendar os mecanismos de construção desses discursos para que, a partir da materialidade dos enunciados observados, possamos descrever seus efeitos de sentido no que diz respeito às estratégias enunciativas a fim de fazer crer na realidade relatada por suas reportagens.

Utilizando os preceitos da análise do discurso de linha francesa, sua preocupação com o contexto sociohistórico, bem como sua característica de disciplina de entremeio, instalada em uma região transdisciplinar "na qual será possível enxergar os entrecruzamentos que estão na base da relação entre a língua, o sujeito, a sociedade e a História"', analisamos a matéria da publicação intitulada Dividir para governar, com o subtítulo $O$ voto dos pobres se distancia do voto da classe média em intensidade inédita. Esse divórcio facilita a exploração e a manipulação eleitoral ${ }^{4}$. Ademais, buscamos realizar uma breve leitura do todo da revista para traçar as peculiaridades de seu discurso, chegando, dessa forma, ao estilo da publicação, que vai na contramão da tendência quase integral do discurso jornalístico em obedecer às coerções do gênero e priorizar o tom de mediania da voz.

\section{PREOCUPAÇÕES TEÓRICAS: ALGUMAS ESPECIFICIDADES DO DISCURSO JORNALÍSTICO}

Quando observamos o discurso jornalístico, podemos destacar as instâncias da enunciação (sujeito, lugar e espaço) unindo-se para manifestar determinada experiência de mundo, determinado sentido. A enunciação, ato de fala deduzida da materialidade do enunciado, é individual porquanto ditada pelo sujeito que fala (somente enquanto processo psicofísico), e social porque construída de acordo com a seleção de signos pré-disponíveis na linguagem. Por ser social, o signo também é dialógico, ou seja, os enunciados articulam-se no contexto da interlocução, levando em conta outros enunciados preexistentes, além dos de seus interlocutores. "O dizer do enunciador é a reprodução inconsciente do dizer de seu grupo social. Não é livre para dizer, mas coagido para dizer o que seu grupo social diz". Bakhtin já dava papel de destaque ao contexto da enunciação, puro produto da interação social, e acrescentava: a palavra deve ter "um caráter intangível e acima das diferenças de classe, a fim de abafar ou de ocultar a luta dos índices sociais de valor que aí se trava, a fim de tornar o signo monovalente"

Dessa maneira, ao retomarmos o conceito de dialogismo de Bakhtin, percebemos o discurso como uma pluralidade de vozes que o constituem e entendemos que a palavra não é neutra, mas carregada, ocupada pelo discurso do outro. Observamos que, no enunciado jornalístico, as diferentes vozes aparecem, principalmente, enquanto "heterogeneidades mostradas e marcadas", ou seja, 
como citações de especialistas e pessoas autorizadas a dizer o que dizem pelo conhecimento da técnica. O poder-saber opera, no enunciado jornalístico, incessantemente, mascarando outras vozes e reafirmando sua função referencial.

De fato, o discurso jornalístico sustenta-se em sua função referencial para constituir-se informativo e documental, para fazer-se porta-voz da realidade. Não é de estranhar que as matérias e reportagens estejam repletas de citações e entrevistas, salpicadas de fotografias, tabelas e dados estatísticos. Esses procedimentos são recursos aos sinais de marcação da remetência ao real, pois são eles que sustentam a verdade contida no enunciado jornalístico. Juntamente com a estratégia obrigatória do lead (quem, o quê, onde, quando, como), que além de atuar como referência ao real também sustenta as categorias de atualidade, universalidade e periodicidade, esses recursos agem como suposição de um real comunicado em sua plenitude. O sujeito que conta a história e que, muitas vezes, toma conhecimento dos fatos utilizando apenas o telefone é apagado. A propriedade de ilusão referencial é mascarada e a realidade como algo construído no e pelo discurso fica obscurecida.

Porém, se examinarmos a natureza desses índices de referencialidade, veremos que se trata apenas de um efeito de real: as entrevistas, citações, fotos e até o próprio acontecimento narrado são escolhas, seleções que supõem algo excluído, um não-dito. Esse efeito de real é instalado para estabelecer o caráter de verdade e, conseqüentemente, a credibilidade, pois "no jornalismo o jogo da credibilidade se joga sobre o sucesso da referencialidade suposta" ${ }^{8}$.

Assim, ocupando lugar de destaque na sociedade contemporânea na medida em que exerce determinado papel formador, o discurso jornalístico apresenta-se textualmente pela predominância da narração em terceira pessoa e pelo apagamento das marcas do sujeito da enunciação no enunciado. Além disso, ele é comumente descrito como relato de um fato, mas nunca pronunciado como seleção de um fato em detrimento de outro. Ora, toda seleção está impregnada de subjetividade latente, mas é dissimulada, no discurso jornalístico, por um efeito de sentido de objetividade de um não-eu. Isso faz com que o referencial externo desapareça, criando um referencial interno materializado pelo fato narrado. Surge aí o efeito de verdade. Uma verdade construída segundo o olhar de quem narra. Como nos atesta Baccega, o discurso jornalístico cumpre sua função de dissimular a realidade:

Esse discurso jornalístico, uma das manifestações do discurso da comunicação, mascara a realidade. No entanto, difunde-se na sociedade que ele mostra mil faces do mesmo acontecimento. Essa é uma postura dita liberal que afirma: se queremos ter objetividade - já que todo discurso está eivado de subjetividade -, basta dar lugar, numa sociedade, a essa pluralidade de vozes que o constitui. Esse "sofisma" aquieta as consciências. Sofisma porque, evidentemente, se uma sociedade tem uma pluralidade de vozes, uma delas exercerá a hegemonia e procurará mantê-la, ou seja, não permitirá que todas as vozes falem com o mesmo caráter de verdade. Isso quando conseguem falar ${ }^{9}$.
7. AUTHIER-REVUZ, Jacqueline. Heterogeneidades enunciativas. Cadernos de Estudos Lingüísticos. Campinas: Unicamp/IEL, n. 19, p. 28,1990 .

8. GOMES, M. Jornalismo e ciências da linguagem. São Paulo: Hacker, 2000. p. 30 .

9. BACCEGA, Maria Aparecida. Comunicação e linguagem: discursos e ciência. São Paulo: Moderna, 1998. p. 58. 
comunicação \& educação • Ano XII • Número 1 • jan/abr 2007

\section{O DISCURSO HEGEMÔNICO DE VEJA E A CONSTRUÇÃO DA IMAGEM DO POBRE}

Com o intuito de demonstrar como o discurso de Veja opera e tendo em vista suas peculiaridades, analisamos o exemplar de 6 de setembro de 2006, especialmente a matéria Dividir para governar ${ }^{10}$. Assim, o sujeito enunciador inicia a reportagem relatando um fenômeno novíssimo desde a primeira eleição democrática em 1985: a distância entre as intenções de votos da classe média e as das camadas menos favorecidas ao candidato do PT, Luiz Inácio Lula da Silva, para a campanha presidencial de 2006. A questão levantada pela reportagem, que segundo Veja intriga os especialistas, gira em torno de compreender (ou explicar) por que 52\% dos pobres votam em Lula, contrapondo os $36 \%$ da classe média com a mesma intenção de voto. "Estaria o Brasil reeditando $o$ anacronismo da luta de classes $^{11}$ em pleno alvorecer do século XXI?"

De fato, pela construção sintática mencionada antes, observamos os sentidos que se instauram: o semanário considera a luta de classes uma questão obsoleta, que já foi ultrapassada pelo alvo liberalismo contemporâneo. Nessa perspectiva, o substantivo alvorecer contém vestígios importantes e funciona como furos no tecido lingüístico por onde escoam sentidos impregnados de uma ideologia de valorização das classes altas, que atua desqualificando o que o semanário chama de pobres. A expressão invenção anacrônica demonstra efetivamente o apagamento das formas da luta de classes na contemporaneidade, ocasionando, de um lado, o silenciamento das desigualdades sociais e, de outro, a supervalorização dos aspectos liberalistas, internacionalistas e tecnológicos do século XXI.

Mediante a conceituação de formação discursiva de Michel Foucault, podemos compreender como a repetição de certo signo é capaz de marcar determinada formação discursiva ${ }^{12}$, que segundo o filósofo não se restringe ao conflito de classes, já que o poder também está localizado em "microesferas de poder"13. Dessa forma, o substantivo pobre mostra-se valioso numa análise preocupada em compreender as relações de poder que estão nas bases da constituição do sentido: empregado 19 vezes durante a matéria, o termo exemplifica nitidamente a característica polissêmica do signo, ou seja, sua plurivalência. De fato, essa diversidade de significações possíveis, que faz emergir sentidos diversificados, permite ao signo ser o local de manifestação da ideologia, uma vez que "a palavra revela-se, no momento de sua expressão, como o produto da interação viva das forças sociais" ${ }^{14}$. Assim, partindo da significação estritamente econômica do substantivo pobre, observa-se um deslizamento de sentido o qual faz emergir outros tipos de pobreza - cultural, educacional, moral e, por que não acrescentar, pobreza de dignidade. Em contrapartida, o enunciador utiliza uma variação maior de termos para designar o que ele chama de classe média: formadores de opinião, parcela mais esclarecida, eleitorado médio, público de maior instrução, todos claramente positivos. Instaurando a contradição pobre versus classe média, o sujeito da enunciação atua claramente em favor do último, construindo uma imagem pejorativa e auxiliando na mitificação do pobre como indigno e incapaz de exercer a cidadania. 
Assim, apesar de (re)afirmar o aumento da renda da classe baixa e do sucesso do Programa Bolsa Família, o enunciador assinala que Lula "conseguiu encenar como nenhum outro presidente recente o papel de pai dos pobres, figurino celebrizado por Getúlio Vargas" ${ }^{15}$. Resgatando o poder-saber da história oficial dos acontecimentos, em especial o episódio do golpe tramado pela UDN - União Democrática Nacional, contra o populismo de Getúlio Vargas e, dez anos mais tarde, do golpe que depõe João Goulart, o tom de voz do semanário atua em seu poder de tudo ver, aproximando passado e presente e deixando margens para prever o futuro: "No último governo de Getúlio Vargas, frações mais elevadas da classe média, ameaçadas pelo aumento da participação popular, juntaram-se à UDN para tramar o golpe contra o pai dos pobres"16; e reforça: "as mudanças promovidas pelo presidente João Goulart, como as reformas de base, opuseram os mais pobres aos setores médios e ricos, influenciados pelo discurso conservador que resultou no golpe militar de $1964 " 17$.

Ademais, o emprego do verbo encenar produz sentidos próximos aos observados nas páginas dessa mesma publicação durante a cobertura eleitoral de $2002^{18}$. A leitura de exemplares desse período demonstra que Veja constrói a imagem do personagem Lula tendo como vetor de sentido a falsidade, colaborando com a instalação de efeitos de dúvida e medo. É o que certamente ocorre no enunciado em questão, no qual o enunciador (re)afirma o medo e a desconfiança, construindo seu discurso de um modo que atua na intensidade e dispensa a mediania da voz. Daí depreendemos as estratégias discursivas de Veja para fazer crer na realidade relatada em suas reportagens que, rompendo o contrato do gênero, age como contraponto ao modelo de jornalismo consagrado no Brasil. Dessa forma, tendo como mote o jornalismo crítico, a publicação opera como porta-voz principal da ideologia da classe dominante, instaurando sentidos hegemônicos. O mais preocupante em relação a eles é, sem dúvida, a construção de significações pejorativas da imagem do pobre: sem instrução e cultura, desprovido de conhecimento, impossibilitado de votar adequadamente e incapaz de exercer a cidadania. De fato, isso se confirma ao observarmos a ilustração da matéria: um grande fosso simula a distância entre as intenções de voto da classe média e as dos pobres. De um lado, a imagem de um homem de terno e gravata representa a ilustre classe média. De outro, tendo uma fábrica ao fundo, um operário de macacão com uma enorme chave de fenda nos braços. Nada muito significativo se não fosse um detalhe: o operário tem cabeça e chapéu diminutos se comparados ao corpo.

Sendo assim, o enunciador constrói para si o simulacro da intensidade, da tonicidade e do impactante, reafirmando a valorização de um valor de verdade contido no enunciado. Nota-se o ethos que fala alto e do alto e, através de um modo de dizer recorrentemente enfático, o enunciador valoriza sua soberania. Observamos o tom de voz que mais se desvela: a enunciação que não relativiza, mas ataca e defende diretamente.
15. DUAILIBI, op. cit., p. 66.

16. Ibid.

17. Ibid.

18. AZEVEDO, A. F. O discurso jornalístico: revistas Época e Veja na cobertura eleitoral de 2002. In: Congresso Brasileiro de Ciências da Comunicação. São Paulo: Intercom, n. 28, 2005. 1 CD-ROM. 


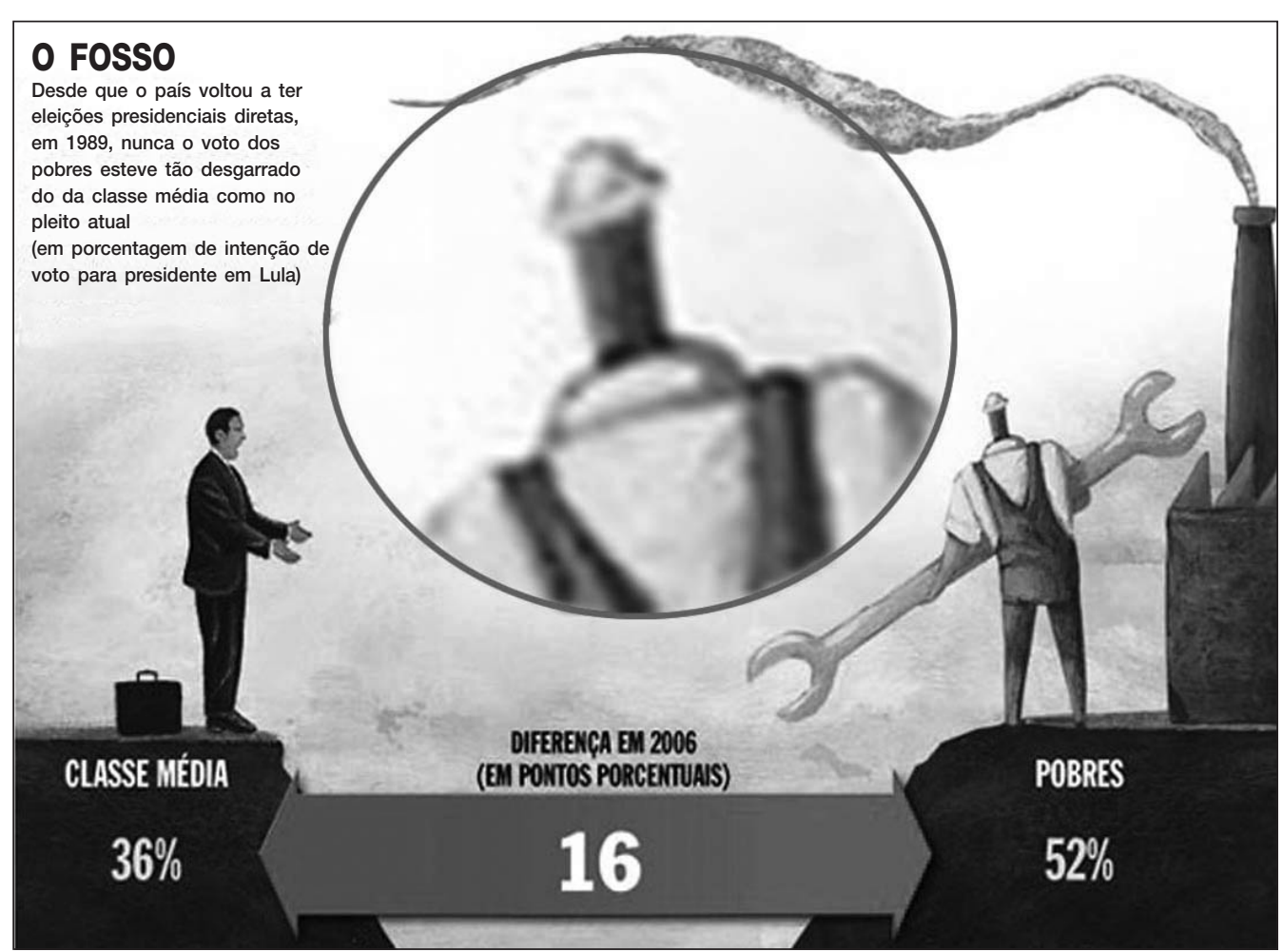

No destaque, cabeça de operário desproporcionalmente inversa à da ilustração do executivo. Fonte: Revista Veja. Montagem sobre fotos de John Berry, Royalty-Free/Getty Images.

\section{CONSIDERAÇÕES FINAIS}

De fato, por meio do conceito do dialogismo bakhtiniano compreendemos as muitas vozes que operam no interior do discurso e que aparecem, no gênero jornalístico, como estratégias enunciativas. Se, por um lado, a plurivocalidade (re)afirma o poder-saber do discurso jornalístico através de citações eloqüentes de especialistas diversos, por outro, ampara o sofisma liberalista, o qual difunde a idéia de que ele mostra mil faces do mesmo acontecimento. É desse modo que as estratégias discursivas são aplicadas de acordo com os ideais do gênero jornalístico mediante coerções desse mesmo gênero. Expliquemo-nos: ao recorrer à noção de gênero discursivo de Bakthin, observamos que "o gênero discursivo diz respeito às coerções estabelecidas entre as diferentes atividades humanas e os usos da língua nessas atividades, ou seja, as práticas discursivas implicam necessariamente coerções"19.

Dessa forma, entendemos que determinada esfera da atividade humana produz enunciados concretos e únicos, ou seja, que estão contidos em deter-

19. BRAIT, Beth. O discurso sob o olhar de Bakhtin. In: GREGOLIN, M. R.; BARONAS, R. (Orgs.). Análise do discurso: as materialidades do sentido. São Carlos: Claraluz, 2003. p. 27. minados gêneros os quais, por sua vez, implicam em coerções. Apesar disso, os falantes não estão impossibilitados de criar, modificar ou alterar o gênero a que se sujeitam. De fato, durante nosso processo de análise notamos que Veja atua quebrando esses contratos genéricos, alterando nitidamente as coerções, como, por exemplo, quando age cerceando vozes. Assim, ao operar num tom de voz autoritário e autorizado pelo seu conhecimento da técnica, o semanário 
impõe um único dizer contido em um único modo de dizer, tal qual retrata Nilton Hernandes: "A revista também se faz passar por dona de um saber tão abrangente que julga até mesmo as opiniões dos especialistas que consulta. Essas vozes, porém, só são ouvidas se reafirmarem o ponto de vista da publicação. Veja constrói um discurso autoritário" ${ }^{20}$.

Quando instaura vozes, elas ecoam seu próprio falar, eterno reflexo em que a refração procura ser permanentemente apagada. Suas vozes operam em uníssono e a aparente plurivocalidade mascara seu autoritarismo latente. E não é só: ao utilizar adjetivos e termos com traços avaliativos intensos, que agem como enaltecedores de determinado valor, Veja rompe com a coerção genérica a qual prevê o apagamento do sujeito enunciador, instalando seu eu que fala alto e do alto, construindo sua marca e reforçando seu estatuto de verdade: "Veja é um simulacro do sujeito da enunciação, um 'autor' de papel. Essa identidade aparece condensada por meio de uma marca"21.

Dessa forma, a marca Veja, o olho especular que tudo vê, robustece seu poder-saber, colocando-a para além das publicações editoriais semanais e ressaltando sua importância como representante de modos de ver, sentir e ser hegemônicos. Temos finalmente, pela análise da materialidade do enunciado da revista, um esboço de como seu discurso atua conduzindo condutas, o que nos permite resgatar os escritos de Deleuze acerca das palavras de ordem:

Os jornais, as notícias, procedem por redundância, pelo fato de nos dizerem o que é 'necessário' pensar, reter, esperar etc. A linguagem não é informativa nem comunicativa, não é comunicação de informação, mas - o que é bastante diferente - transmissão de palavras de ordem ${ }^{22}$.

Resumo: Este artigo efetua uma análise crítica da revista de assuntos gerais e atualidades Veja, apontando os sentidos hegemônicos que permeiam suas páginas. Utilizando os preceitos da análise do discurso de linha francesa, efetuamos a (re)leitura do exemplar de 6 de setembro de 2006 com o intuito de demonstrar, pela observação de seu modo de dizer intenso e convicto, as estratégias de construção de seus discursos e a produção dos efeitos de sentidos que atuam constituindo a imagem do pobre em suas páginas.

Palavras-chave: revista Veja, análise do discurso, discurso jornalístico, hegemonia.
Abstract: This article makes a critical analysis of the general subject's magazine Veja, showing its hegemonic meanings. Using the French Speech Analysis rules, were made a reading of September $6^{\text {th }}$, 2006 Veja unit, intending to exhibit, by looking at its deep and convincing speech, the speech's construction strategy and the meaning effects production that building up the poor's people image.

Keywords: Veja magazine; speech analysis; journalistic speech; hegemony.
20. HERNANDES, Nilton. A revista Veja e o discurso do emprego na globalização: uma análise semiótica. 2001. Dissertação (Mestrado)-Faculdade de Filosofia, Letras e Ciências Humanas, Universidade de São Paulo, São Paulo, 2001. p. 150 .

21. Ibid., p. 53.

22. DELEUZE, Gilles; GUATTARI, Félix. Mil platôs. Rio de Janeiro: Editora 34, 1995. p. 16. v. 2. Capitalismo e Esquizofrenia. 